Journal of Communication Pedagogy
2018, Vol. 1(1) 124-131
Jo The Author(s) 2018
$\begin{array}{r}\text { COMMUNICATION } \\ \text { PEDAGOGY }\end{array}$
Reprints and permissions: http://www.csca-net.org
DOI:10.31446/JCP.2018.20
Central States Communication Association

\title{
Best Practices for Facilitating Communicaton-Centered Professional Development for Non-Communication Faculty
}

\author{
Stephanie Norander
}

\begin{abstract}
Communication-across-the-curriculum (CxC) programs commonly support non-communication faculty by crafting robust professional development learning experiences. This article presents 10 best practices for facilitating professional development designed to support the teaching and learning of communication competencies in non-communication disciplines. These practices draw on lessons learned from a successful professional development course facilitated by the CxC program at the University of North Carolina at Charlotte. Grounded in a situated communication pedagogy framework, these best practices reflect a communication-centered approach to professional development, thus extending scholarly discourse and practices surrounding CxC programs, communication pedagogy, and professional development of faculty.
\end{abstract}

Communication-across-the-curriculum $(\mathrm{CxC})$ programs support non-communication faculty in facilitating teaching and learning of communication in the disciplines (see Dannels \& Gaffney, 2009 for an overview of $\mathrm{CxC}$ scholarship). One common way for $\mathrm{CxC}$ programs to provide such support is through designing and delivering professional development opportunities. This article presents 10 best practices for facilitating what I term communication-centered professional development for noncommunication faculty. These best practices emerged from a successful professional development course created and facilitated by the $\mathrm{CxC}$ program at the University of North Carolina at Charlotte (UNCC) to support non-communication faculty teaching communication intensive courses (also known as oral communication intensive and writing intensive courses) in the disciplines. This course was a six month, blended, intensive learning experience with the goal of facilitating a course design and implementation process grounded in Dannels's (2001) situated communication pedagogy framework.

Stephanie Norander, Department of Communication Studies, University of North Carolina at Charlotte, Charlotte, NC CONTACT: Stephanie Norander snorande@uncc.edu

The CxC program at UNC Charlotte is led by Stephanie Norander, Ph.D., Executive Director, and Dr. Heather Bastian, Associate Director. The author would like to acknowledge and express appreciation for Dr. Bastian's work in co-creating and co-facilitating the professional development course described in this article. 


\section{Best Practice \#1: Foreground Communication Theory and Praxis}

Although foregrounding communication theory and praxis may sound like an obvious best practice when facilitating communication-centered faculty development, it is important to make explicit this foregrounding for non-communication faculty. Faculty who are unfamiliar with $\mathrm{CxC}$ activities often ask questions such as "why can't students learn how to communicate in a public speaking course?" or "why can't you just come into my class and do a workshop on speaking or writing?" By designing the professional development course around Dannels's (2001) situated communication pedagogy framework, questions about the value of teaching and learning communication in disciplinary courses are addressed both upfront and throughout the course. Specifically, faculty need explanation of, and engagement with, the four principles of the communication-in-the-disciplines (CID) model: "(1) oral and written genres are sites for disciplinary learning; (2) communication is a situated practice; (3) communication competence is locally negotiated; and (4) learning to communicate is a context driven activity" (p. 147). The explanation of these principles should be provided in the professional development course introduction. Moreover, examples of each principle taken from different disciplines should be incorporated to help faculty understand how the CID model shapes teaching praxis.

Facilitators need to be aware that adopting a situated communication pedagogy is a substantial paradigmatic shift for some faculty. Adequate time, therefore, should be invested early in the pro-fessional development course to cultivating a deep understanding of the CID model. Additionally, it is important to emphasize the challenges of teaching communication intensive courses in non-communication disciplines. For $\mathrm{CxC}$ facilitators, grounding professional development in a situated communication pedagogy means acknowledging that non-communication faculty are the experts in communicating in their disciplines. The facilitator's role, by contrast, is to provide guidance in, and a structure for, designing learning experiences that allow students to develop communication competencies that are relevant and valued in their discipline.

\section{Best Practice \#2: Identify Specific Institutional and Faculty Needs}

Identifying specific faculty needs allows for the design of a responsive and locally situated faculty development experience. A Needs-Centered-Model approach is especially applicable to designing professional development for faculty as adult learners (Beebe, Mottet, \& Roach, 2013). Conducting needs identification prior to the design of professional development helps orient faculty to the purposes of the learning experience and engages them in the design process (for an example of using needs assessment to establish a campus CxC program, see Morreale, Shockley-Zalabak, \& Whitney, 1993). This needs assessment sets the tone for a collaborative and community-based learning environment. In addition, facilitators communicate credibility and establish legitimacy of the professional development experience to participants when their feedback is explicitly incorporated into the professional development.

To implement this best practice, a professional development needs identification survey can be administered to participants or potential participants that (a) identifies specific needs for professional development in incorporating communication instruction in non-communication courses; (b) creates awareness of the $\mathrm{CxC}$ program and building anticipation for forthcoming professional development; and (c) gathers information on interest in, and feasibility of, delivery formats (e.g. online, face-to-face, blended). Sample survey questions include:

(1) What types of oral communication activities and assignments do you incorporate or are interested in incorporating? 
(2) What types of written communication activities and assignments do you incorporate or are interested in incorporating?

(3) What challenges do you face when incorporating communication instruction into your classes (e.g., integrating communication into course objectives, designing assignments, scaffolding learning through activities and assignments, facilitating in-class communication activities, providing students with meaningful formative feedback on communication assignments, and grading and providing summative evaluation of communication assignments)?

(4) Which of the following topics related to incorporating communication into your teaching would you like to explore further (e.g., designing effective, course relevant communication assignments; incorporating brief in-class communication instruction into class activity; grading and evaluating oral and written communication activities; providing useful feedback on drafts and works in progress; developing and incorporating revision activities; organizing effective peer review activities; working with multilingual students; addressing grammar, usage, and mechanics; addressing pronunciation, articulation, dialect, and nonverbal behaviors; incorporating communication instruction in online courses)?

In addition, information about the course, academic department, and teaching experience should be collected.

\section{Best Practice \#3: Create a Flexible and Personalized Learning Environment}

One obstacle to faculty participaton and engagement in professional development opportunities is lack of time and flexibility in scheduling. Moreover, as Fowler and Bond (2016) established, the traditional "one-size-fits-all" faculty development workshop or institute mirrors the one-size fits all curricular delivery model that has come under much scrutiny in the college classroom. Because communication scholarship has been at the forefront of integrating innovative technology to support meaningful learning, it makes sense, then, that communication-centered professional development make strategic use of technology in working with faculty learners. This best practice was implemented at UNCC by creating a blended learning environment that permitted faculty the flexibility to participate remotely combined with personalized consultation, which allowed for faculty to have some control over the time, place, and pace of the learning (Maxwell, 2016).

The professional development course at UNCC is launched with a face-to-face meeting. Then, over the next four weeks, faculty work through a series of weekly online modules developed in Canvas. Each module is introduced at the start of the week with a WebEx videoconference that faculty either participate in live or watch recorded. In addition, faculty participate in two individual consultations, either in person or via videoconference. Finally, during the following semester when faculty are teaching their communication intensive course, they participate in two face-to-face group meetings.

\section{Best Practice \#4: Start With Course Design}

Because a well-designed course is essential to facilitating student learning, the first step is articulating clear, specific, and concrete course learning outcomes. For some non-communication faculty, this involves a radical transformation to adopt backward design principles. For other non-communication faculty, the shift may be less daunting, but the key is to integrate communication into the design of 
communication intensive courses. By contrast, a non-integrated communication intensive course gives primacy to disciplinary content with oral and written assignments added to the course to satisfy the required number of presentations or papers. Helping faculty shift to an integrated approach requires an understanding and adoption of backward design principles and course alignment. Implementing this best practice requires three steps. First, faculty must be introduced to backward design principles and provided with additional resources to explore these principles (Wiggins \& McTighe, 2005).

Second, faculty should answer questions about any situational factors that can shape the learning environment (Fink, 2013). These situational factors include (a) learner characteristics (e.g., Who are the students who will be taking the course? What prior learning have they had? What prior experiences with speaking and writing have students had?), (b) instructor characteristics (e.g., What prior experiences, knowledge, skills, and attitudes do you have in terms of the subject of this course? What are your strengths as a teacher and how can you play to those strengths?), and (c) course and subject characteristics (e.g., Is this an existing course? If so, have you taught this course before? What was the feedback from students previously?) Third, facilitators should work closely with faculty in drafting course learning outcomes that are relevant, clear, and specific; can be assessed; and are reflective of the integration of communication and content by providing feedback and consultation, either individually or in small groups, on the draft learning outcomes.

Strong, well-integrated learning outcomes will serve as a foundation as faculty take the next steps in developing speaking and writing assignments. Moreover, covering these bases should mediate, if not eliminate, faculty perceptions that "time spent teaching communication is time not spent teaching content" and cultivate instead an understanding of oral and written communication genres as sites for disciplinary learning.

\section{Best Practice \#5: Cultivate a Sense of Community}

Creating a community among cross-disciplinary faculty has benefits that extend beyond a single professional development experience. Non-communication faculty teaching communication intensive courses often struggle with similar challenges and can share ideas and teaching strategies that address these challenges. Moreover, facilitating a sense of community among cross-disciplinary faculty can help them realize that "communication competence is locally negotiated" (Dannels, 2001, p. 150) within disciplines. There are many strategies for cultivating community among faculty. As a facilitator, it is imperative to establish an environment where peer learning can occur, rather than an environment where a communication expert teaches non-communication faculty exclusively. This can be accomplished by making learning with, and from, a community of peers an explicit goal of the professional development course and communicating clearly to faculty that the facilitator's role is to learn from them what is important about communicating in their discipline.

In addition, structured opportunities should be provided for faculty to connect and learn from each other throughout the professional development experience. Implementing a peer review and feedback process into the professional development course is an excellent way to do this. For example, sharing draft high stakes communication assignments across disciplines is a constructive way for faculty to note firsthand the similarities and differences in how different disciplines socially construct communication competence, receive valuable feedback from a peer outside the discipline, and, at the same time, gather ideas for their own teaching by providing feedback to others and making connections with faculty across disciplines that they otherwise may not have. 


\section{Best Practice \#6: Make Reflection Central to Professional Development}

This practice may sound obvious to communication scholars, but in truth many faculty development workshops and programs neglect the central role of reflection to learning and growth as a teacher. Reflection plays an especially crucial role for non-communication faculty seeking to expand their abilities to teach disciplinary communication intensive courses. Faculty must first uncover their assumptions about discipline-specific norms, expectations, and relevant genres of communication before they put into practice the principle of communication as a situated practice. Guided reflection prompts help non-communication faculty discover what they and their discipline values about communication and why. This reflection, in turn, can help them understand how to make explicit for students the norms and expectations for communicating as, for example, a biological sciences major. Teaching communication intensive courses in the disciplines is both rewarding and challenging. For many faculty, particularly those developing such a course for the first time, the thought of emphasizing oral and written communication is daunting.

Through guided reflection prompts, faculty are able to acknowledge their strengths, challenges, concerns, and questions about teaching (Dannels, 2015). In a blended learning environment, it is easy to implement this best practice by creating a weekly reflection exercise using short prompts relevant to the week's topic. Personal teaching reflections should remain private unless individuals want to share with peers voluntarily. Facilitators should read and comment on reflections, while keeping in mind that the purpose of practicing reflection is to support individual growth as a teacher. Below is an example reflection prompt:

Last week you articulated characteristics of communication in your discipline. This week, consider what your students know about those specific characteristics that you listed. Where would they have learned them if at all? Who would have taught them if anyone? How would they have been taught them if at all? How much practice will they have had if any? Then consider, what does this mean for me as an instructor of this course? Given the reality of students' communication backgrounds, what might I need to do as an instructor to help students learn how to communicate in the discipline?

\section{Best Practice \#7: Support Faculty Through Implementation of Changes in Teaching Practice}

There is no doubt that the scope and breadth of faculty development programs at U.S. universities has expanded in recent years (Condon, Iverson, Manduca, Rutz, \& Willett, 2016). Contemporary scholarship conducted on faculty professional development demonstrates that single, one-time workshops and instructional content without consultation and coaching are less likely to have a meaningful impact on teaching practices than more in-depth approaches (Condon et al., 2016). The best practice of supporting faculty beyond a single workshop should be a point of distinction for a communication-centered approach to professional development. For facilitators working with non-communication faculty, this can serve multiple purposes. Faculty who are supported through both the design and implementation 
phases of communication intensive courses are likely to experience an increase in their comfort level with integrating oral and written communication. And, providing support through implementation provides facilitators with invaluable feedback on how a situated communication pedagogy works across various classroom environments.

There are several ways that course implementation support can be accomplished. For example, at UNCC, faculty participate in two informal peer group feedback sessions-one toward the beginning of the semester and one toward the end of the semester-during the semester they are teaching their communication intensive course. The purpose of these sessions is to provide both facilitator and peer support and allow faculty to discuss what is and is not working. In addition, faculty are encouraged to contact the $\mathrm{CxC}$ administrators with any questions or challenges they have while teaching the course. In this way, faculty receive ongoing support, advice, and encouragement for their teaching practice. At the same time, the $\mathrm{CxC}$ facilitators are able to assess the implementation phase to know what aspects of the professional development course need to be reinforced or revised in the future.

\section{Best Practice \#8: Provide Explicit Instruction and Feedback on Communication Assignment Design}

For non-communication faculty, creating, planning, and evaluating communication assignments is challenging. Faculty express feeling overwhelmed, especially with providing feedback on, and evaluating, presentations and written assignments. "All that grading!" is a common negative refrain when faculty are assigned to teach communication intensive courses. Many problems emerge when communication assignments are not aligned with the course outcomes and when the criteria for communication assignments are unclear. Similar problems occur when high stakes communication assignments are due at the end of the semester with little to no scaffolding of competency development throughout the semester. Also, in some non-communication fields, it is common to find misperceptions about teaching and learning communication competencies. For example, faculty may believe that effective feedback on speech outlines and paper drafts equates to marking all errors. Dannels, Gaffney, Kedrowicz, and Roth's (2014) model for planning communication assignments is an excellent departure point for guiding faculty through the process of communication assignment design. Faculty should first answer explicit questions on their planned assignments about alignment with course outcomes; they then identify and map the scaffolding needs for their students to achieve the desired learning outcomes of the assignment.

Based on this map, faculty can sequence a major communication assignment so that students have the opportunity to learn from a draft-feedback-revision process. Faculty then can plan for low stakes assignments that provide learning scaffolds for a major assignment. Finally, facilitators should work with faculty on developing a formative feedback and summative evaluation plan for major assignments. Formative feedback should include a combination of instructor-, peer-, and self-feedback throughout the semester. It is useful to share with faculty examples of how to incorporate these different sources of formative feedback across the development of a major assignment. Having gone through this guided process of communication assignment design, faculty then are able to create robust learning activities that intentionally provide students opportunities to develop communication skills and engage deeply with the content area. 


\section{Best Practice \#9: Gather Meaningful Feedback}

Facilitators should take necessary steps to gather feedback from participants that provides meaningful data on faculty learning and engagement as well as program assessment. The CxC program at UNCC utilizes self-report data from faculty, both immediately following each module and in follow-up sessions during and after the implementation semester. This feedback gathering not only allows for ongoing assessment and minor revision of the development modules while faculty are engaging in them, but also for developing a more holistic understanding of the value of the professional development course in transforming teaching practice. This feedback can be invaluable in presenting arguments for sustaining support of the professional development course specifically and the $\mathrm{CxC}$ program generally.

\section{Best Practice \# 10: Offer Incentives and Champion Faculty Efforts}

As stated in the Guiding Principles for CxC (Dannels et al., 2014), faculty should be offered incentives for their participation. Individual stipends for faculty who complete the professional development course are an excellent way to reward work on improving teaching. However, if financial incentives are not possible, there are other ways to celebrate and champion faculty participants. These ways include (a) actively recruiting participants for presentation of their work at local, regional, and national conventions or conferences; (b) sending letters of recognition for all participants to their department chair as well as their college dean; (c) hosting a reception to recognize all faculty participants in which the provost and college deans also are invited; (d) organizing a campus showcase for faculty to share their work in developing communication intensive courses, which can be done in partnership with other campus programs that may host similar events (e.g., Center for Teaching and Learning); (e) featuring faculty participants on the program website and in the program newsletter. Regardless of how participants are celebrated and championed, it is best to shine a spotlight on them in any way possible. By doing so, $\mathrm{CxC}$ facilitators can contribute to building a campus culture where teaching and learning excellence is honored and appreciated.

\section{Conclusion}

These 10 best practices are derived from experience designing and implementing a professional development course grounded in a situated communication pedagogy framework. Using a communication-centered approach to professional development has a positive impact on individual non-communication faculty participants and increases knowledge about the value and centrality of communication in teaching and learning as a whole. The best practices of facilitating communicationcentered professional development are adaptable to $\mathrm{CxC}$ programs and initiatives of different size and scale at other campuses. 


\section{References}

Beebe, S. A., Mottet, T. P., \& Roach, K. D. (2013). Training and development: Communication for success (2nd ed.). Boston, MA: Pearson.

Condon, W., Iverson, E. R., Manduca, C. A., Rutz, C., \& Willett, G. (2016). Faculty development and student learning: Assessing the connections. Bloomington, IN: Indiana University Press.

Dannels, D. P. (2001). Time to speak up: A theoretical framework of situated pedagogy and practice for communication across the curriculum. Communication Education, 50, 144-158. doi:10.1080/03634520109379240

Dannels, D. P. (2015). 8 essential questions teachers ask: A guidebook for communicating with students. New York, NY: Oxford University Press.

Dannels, D. P., \& Gaffney, A. L. H. (2009). Communication across the curriculum and in the disciplines: A call for scholarly cross-curricular advocacy. Communication Education, 58, 124-153. doi:10.1080/03634520802527288

Dannels, D. P., Gaffney, A. L. H., Kedrowicz, A. A., \& Roth, A. D. (2014, November). Communication across the curriculum and general education: Evolving best practices. Paper presented at the meeting of the National Communication Association, Chicago, IL.

Fink, L. D. (2013). Creating significant learning experiences: An integrated approach to designing college courses. San Francisco, CA: John Wiley \& Sons.

Fowler, S., \& Bond, M. A. (2016, March 7). The future of faculty development in a networked world. Educause Review. Retrieved from https://er.educause.edu/articles/2016/3/the-future-of-facultydevelopment-in-a-networked-world

Maxwell, C. (2016, March 4). What blended learning is and isn't. Blended Learning Universe. Retrieved from https://www.blendedlearning.org/what-blended-learning-is-and-isnt/

Morreale, S., Shockley-Zalabak, P., \& Whitney, P. (1993). The center for excellence in oral communication: Integrating communication across the curriculum. Communication Education, 42, 10-21. doi:10.1080/03634529309378909

Wiggins, G. P., \& McTighe, J. (2005). Understanding by design (2nd ed.). Alexandria, VA: Association for Supervision and Curriculum Development. 